\begin{tabular}{|c|c|c|c|c|c|c|}
\hline \multirow{4}{*}{ Impact Factor: } & ISRA (India) & $=4.971$ & SIS (USA) & $=0.912$ & ICV (Poland) & $=6.630$ \\
\hline & ISI (Dubai, UAE & $=0.829$ & РИНЦ (Russia) & $=0.126$ & PIF (India) & $=1.940$ \\
\hline & GIF (Australia) & $=0.564$ & ESJI (KZ) & $=8.716$ & IBI (India) & $=4.260$ \\
\hline & JIF & $=1.500$ & SJIF (Morocco) & $=5.667$ & OAJI (USA) & $=0.350$ \\
\hline
\end{tabular}

\section{SOI: $\underline{1.1 / \text { TAS }}$ DOI: $10.15863 /$ TAS \\ International Scientific Journal Theoretical \& Applied Science}

\author{
p-ISSN: 2308-4944 (print) e-ISSN: 2409-0085 (online) \\ Year: $2020 \quad$ Issue: 03 Volume: 83
}

Published: 30.03 .2020

http://T-Science.org
QR - Issue

QR - Article
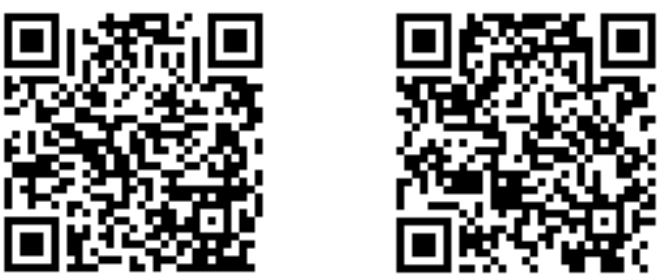

Tarikh M. Dostiyev

Institute of Archaeology and Ethnography of ANAS doctor of historical sciences, Head of Department,

Azerbaijan

dostiyev.tarikh@mail.ru

\title{
LUSTER FAIENCE WARES PAINTED ON MILKY WHITE GLAZE FROM THE TOWN OF SHAMKIR
}

\begin{abstract}
This article presents an overview of the luster ceramics found in Shamkir, of medieval town in the western part of the Republic of Azerbaijan. Lustre - a special colorful composition which gives a metallic shine to the wares. Floral and epigraphic ornaments are dominant in decoration. Often founds in figurative motifs.

Key words: Shamkir, faience, luster ceramics, ornament, calligraphy.

Language: Russian

Citation: Dostiyev, T. M. (2020). Luster faience wares painted on milky white glaze from the town of Shamkir. ISJ Theoretical \& Applied Science, 03 (83), 230-235.

Soi: http://s-o-i.org/1.1/TAS-03-83-45 Doi: crossef https://dx.doi.org/10.15863/TAS.2020.03.83.45

Scopus ASCC: 1204.

\section{ФАЯНСОВАЯ ПОСУДА С РОСПИСЬЮ ЛЮСТРОМ ПО МОЛОЧНО-БЕЛОЙ ПОЛИВЕ ИЗ ГОРОДИЩА ШАМКИР}

Аннотация: Аннотация: В статье представлена информация о люстровой керамике, обнаруженной в средневековом городище Шамкир, которое расположено в западном регионе Азербайджанской Республики. Люстр - особый красочный состав, который придавал изделиям металлический отблеск. В декоре доминируют растительные и эпиграфические орнаменты. Часто встречаются и изобразительные мотивы.

Ключевые слова: Шамкир, фаянс, люстровая керамика, орнамент, каллиграфия.
\end{abstract}

\section{Введение}

Средневековое городище Шамкир расположено в западном регионе Азербайджанской Республики, на левом берегу реки Шамкирчай, на северной окраине села Гядимгала Шамкирского района. С 2007 года на городище Шамкир ведутся стационарные, широкомасштабные археологические раскопки, в результате которых собрана богатая коллекция высокохудожественной люстровой керамики. Считается, что развитию производства люстровой керамики способствовал запрет на использование золотых и серебряных изделий в быту. Люстровая керамика или «фаянсы с росписью люстром», служившие средством имитации в керамике дорогих золотых и серебряных изделий, представляли собой предметы роскоши. Люстром называется сложный красочный состав, наносимый на поверхность глазури после первого обжига керамического изделия и закрепляемый на поверхности в процессе второго, низкотемпературного (600-700 градусов С) обжига. Второй обжиг осуществлялся в восстановительном режиме, в результате чего на поверхности глазури образовывалась тончайшая пленка чистых металлов. Преломление и отражение лучей в этой пленке создавало металлический блеск, цвет которого мог варьировать от серебристого до горчичножелтому и медно-красного [Caiger-Smith, 1985; Koval'. 2010]. Ребристые формы и формы с «ложками», которые часто встречаются среди фаянсовых сосудов с люстровой росписью, также подражают форме металлических изделий [Lavysh, 2017, с. 605]. Известно, что с VIII века 


\begin{tabular}{|c|c|c|c|c|c|c|}
\hline \multirow{4}{*}{ Impact Factor: } & ISRA (India) & $=4.971$ & SIS (USA) & $=0.912$ & ICV (Poland) & $=6.630$ \\
\hline & ISI (Dubai, UAE & $=0.829$ & РИНЦ (Russia & $=0.126$ & PIF (India) & $=1.940$ \\
\hline & GIF (Australia) & $=0.564$ & ESJI (KZ) & $=8.716$ & IBI (India) & $=4.260$ \\
\hline & JIF & $=1.500$ & SJIF (Morocce & $=5.667$ & OAJI (USA) & $=0.350$ \\
\hline
\end{tabular}

люстр применялся в художественном оформлении парадной стеклянной посуды в Сирии и Египте. А образцы художественной керамики с росписью люстром впервые появились в IX веке в Багдаде, Самарре и Фустате [Caiger-Smith, 1985, p. 24-29; Watson 2005, p. 38].

\section{Образцы люстровой керамики из Шамкира}

Фаянсовые изделия с люстровой росписью из археологических раскопок средневекового городища Шамкир представлены в основном образцами чаш, блюд, пиал и кувшинов. Они в основном тонкостенны и легки, выделяются совершенством форм, удачным сочетанием контуров, гармонией пропорции, а уравновешенность и симметрия их декора достигается часто в ритмическом повторении основного мотива в различных сочетаниях и комбинациях. Выделяются фаянсы с росписью люстром по молочно-белой поливе, фаянсы с росписью люстром по синей поливе, люстровые фаянсы с бихромной поливой. Преобладает фаянсовые изделия с росписью люстром по молочно-белой поливе, которые декорированы в основном в «миниатюрном» стиле. Специалисты выделяют три стиля росписи: «монументальный», «миниатюрный» и «кашанский» [Watson, 1985; Koval'. 2010].

В декоре фаянсовой посуды с росписью люстром по молочно-белой поливе доминируют растительные и эпиграфические орнаменты. Часто встречаются и изобразительные мотивы. Очень популярными были чаши, украшенные росписью в монументальном стиле и фестончатой моделировкой тулова. Фрагменты таких чаш известны из раскопа IV городища Шамкир. Эти чаши украшены растительным, геометрическим и эпиграфическим орнаментами, нанесенные росписью люстром (рис.1, 1). В декоре доминируют растительные элементы. Целый экземпляр подобной чаши хранится в Национальном музее истории Азербайджана. Аналогичные чаши, помимо Ирана, известны также из стран Ближнего Востока, Центральной Азии, Восточной Европы и т.д. [Koval', 2010, p. 43, ill. 3: 1; Lavysh, 2017, p.605; Watson, 1985, Fig. 36; Atagarryiev, p. 113-114; Starodub, 1990, p.177183].

Обломок тонкостенного сосуда с невыразительной рельефной моделировкой, обнаруженного на раскопе VI на территории шахристана, украшен восьмиконечными розетками с растительным орнаментом (рис. 1,2).

На блюдах, тарелках, чашах в основном декор располагался концентрическими кругами вокруг центрального медальона. Реже встречаются изделия с узором радиальной тектоникой. Доминируют изделия, украшенные растительной орнаментацией в виде побегов, в частности, растительный узор ислими, нанесенных с люстровой росписью на белом фоне. Так, на глубоком блюде, обнаруженном на раскопе V, узор располагался концентрическими кругами вокруг центрального медальона. В центре композиции, на дне блюда с люстровой росписью нанесен растительный орнамент в виде «ганадлы ислими (крылатый ислими)», «хачалы ислими (раздвоенный ислими)», «буталы ислими (миндаловидные)», который обрамлён кругом. Аналогичный растительный орнамент имеется и на стенке блюда, на широком поясе. Композицию завершает бордюр - эпиграфический орнамент, нанесенный почерком «насх» [Dostiyev et al., 2013, p. 383]. Встречаются образцы с растительными побегами, которые раскручиваются и закручиваются спиралью. Например, растительный побег - простой ислими по спирали покрывает всю внутреннюю поверхность чаши с высоким поддоном (рис. 2, 1). Судя по фрагментам, внутренняя поверхность другой чаши с полусферическим туловом украшена растительным орнаментом - простой ислими, а наружная сторона надписью нанесенной почерком «насх» [Dostiyev et al., 2013, p. 382]. Надо заметить, что сложный, подвижный, легкий и гибкий растительный узор ислими (по арабский ат-таурик), способный в виде бесконечного узора распространяться по поверхности, был очень популярным орнаментом и широко применялся в творчестве средневековых мусульманских художников Ближнего и Среднего Востока [Kerimov, 1983, p. 71-72; Starodub, 2010, p.198].

Примечательна манера исполнения растительного орнамента на днище чаши, обнаруженной на раскопе V. Все элементы люстровой росписи гармонично связаны между собой и «хачалы ислими (раздвоенные ислими)», бутоны на белом фоне создают сложный растительный орнамент на восьмилепестковой розетке (рис. 2, 2). Надо заметить, что «хачалы ислими» и ганадлы ислими широко применялись во всех отраслях декоративного искусства Азербайджана и Ирана в средние века [Kerimov, 1983, p.75].

Растительный орнамент «шахматный» кипарис, весьма характерный для декора люстровой керамики, сохранился на небольшом фрагменте от сосуда с носиком (рис. 2,3). Как правило, это растительный орнамент сопровождался изобразительными мотивами. В этой связи заслуживает внимание сосуд с носиком из археологических раскопок средневекового города Бейлаган, на орнаментальном поясе которого изображены всадники среди кипарисов [Shelkovnikov, 1959, p. 308]. 


\begin{tabular}{|c|c|c|c|c|c|c|}
\hline \multirow{4}{*}{ Impact Factor: } & ISRA (India) & $=4.971$ & SIS (USA) & $=0.912$ & ICV (Poland) & $=6.630$ \\
\hline & ISI (Dubai, UAE & $=0.829$ & РИНЦ (Russia & $=0.126$ & PIF (India) & $=1.940$ \\
\hline & GIF (Australia) & $=0.564$ & ESJI (KZ) & $=8.716$ & IBI (India) & $=4.260$ \\
\hline & JIF & $=1.500$ & SJIF (Morocce & $=5.667$ & OAJI (USA) & $=0.350$ \\
\hline
\end{tabular}

Небольшой фрагмент чаши декорирован стилизованным растительным орнаментом и схематичным изображением птиц (рис. 1, 4). Аналогичный мотив характерен на люстровой керамике Кашана [Watson, 1985, pl. 37; Mason, 1997, p. 113, motif KL.11). Наружная сторона чаши с уплощенным венчиком, украшена геометрическим орнаментом в виде изогнутых линий, пересекающихся видимо в форме восьмерки (рис. 1, 3). Обломки привозной фаянсовой чаши с аналогичным узором известны из археологических раскопок памятников Восточной Европы [Koval', 2010, p. 43, илл.4,1; Lavysh, 2017, p. 606, fig: 3, 1).

Тонкостенная чаша с кольцевым поддоном, полусферическим туловом имеет узор концентрической тектоникой. В центре композиции, на дне чаши расположен сложный геометрический орнамент - гирих, окруженный кругом. Надо заметить, что в исламе фигуры гириха представляют собой подлинное торжество синтеза искусства и математики [Butkevich, 2008, p. 147]). На стенке чаши, на широком поясе сильно геометризованный растительный орнамент. Композицию завершает узкий орнаментальный пояс под венчиком, где нанесена надпись почерком «насх». Надпись нанесена тонкой гравировкой по люстровой росписи. Снаружи верхняя половина стенки чаши украшена горизонтальными полосами, нижняя геометрическим орнаментом (рис. 2,4).

Фрагмент небольшой чаши, обнаруженный на раскопе IV на территории цитадели, также украшен растительными и эпиграфическими элементами. Во внутренней стороне чаши имеется растительный орнамент, нанесенный росписью люстром. Чаша под венчиком окрашена люстром. На нем выгравирована надпись почерком «насх». Снаружи стенка чаши украшена скобкавидными элементами (рис. 1, 6). Аналогичный декор встречается на люстровой керамике Кашана [Mason, 1997, Fig.5).

На фрагменте чаши с плоским венчиком стенка с внутренней стороны украшена орнаментальными поясами с эпиграфическим орнаментом. На нижнем поясе надпись нанесена почерком «насх», а на верхнем поясе имеется куфическая надпись. Судя по фрагменту на днище чаши, в центре композиции был расположен растительный орнамент из четырехлепестковой пальметты (рис. 2,9). На фрагментах кубка сохранились отрывки надписи, выполненные почерком «куфи», и следы растительных элементов (рис. 2, 5).

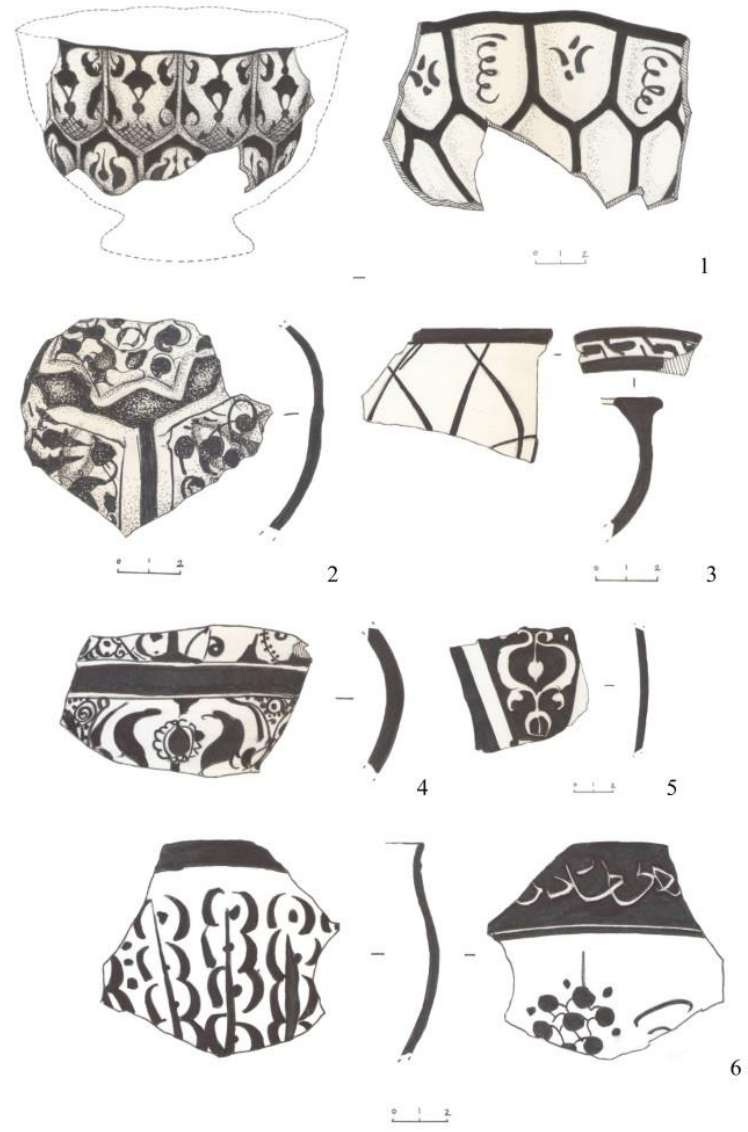

Рис.1. Люстровые фаянсы с росписью по молочно-белой поливе. 


\begin{tabular}{|c|c|c|c|c|c|c|}
\hline \multirow{4}{*}{ Impact Factor: } & ISRA (India) & $=4.971$ & SIS (USA) & $=0.912$ & ICV (Poland) & $=6.630$ \\
\hline & ISI (Dubai, UAE & $=0.829$ & РИНЦ (Russia & $=0.126$ & PIF (India) & $=1.940$ \\
\hline & GIF (Australia) & $=0.564$ & ESJI (KZ) & $=8.716$ & IBI (India) & $=4.260$ \\
\hline & JIF & $=1.500$ & SJIF (Morocce & $=5.667$ & OAJI (USA) & $=0.350$ \\
\hline
\end{tabular}

Орнамент и каллиграфия составляли главенствующее положение в декорировке люстровой керамики. В средневековом мусульманском обществе растительные мотивы оценивались как метафоры рая, а каллиграфия искусством изображения слова. Различные шрифты арабского письма открывали перед гончарами-художниками широкие возможности для творчества. Надписи на люстровой керамике в большинстве своем курсивные. Обычно надпись эпиграфического орнамента читается трудно, так как ее главная функция чисто декоративная [Piotrovskii, 2001; Nikalaeva, 2011]. Надо заметить, что в производстве люстровой керамики каллиграфия переходит из книжных рукописей в область художественной керамики. Живопись часто сопровождается эпиграфическим орнаментом.

Заслуживает внимание декор фрагмента чаши, найденного на раскопе IV. В центре композиции, на днище чаши имеется изображение пернатых, видимо, уток, а люстровый фон изображения украшен тонкой гравировкой с сильно геометризованными растительными элементами. На стенке чаши орнаментальный пояс украшен эпиграфическим орнаментом (рис. 2,7).
Среди люстровой керамики выделяются образцы с изображениями всадников. В центре композиции декора чаш и блюд часто встречаются изображения скачущих всадников на растительном фоне. На дне одной чаши с радиально-центрической композицией имеется схематичное изображение всадника на растительном фоне. У него округлое лицо, миндалевидные глаза, дугообразные брови, спадающие по плечам волосы. Вокруг головы всадника - нимб. Конь под всадником изображен в галопирующей позе. Судя по фрагменту, на расчленённой поверхности стенки чаши изображен этот же мотив в ритмическом повторении (рис. 2, 10).

На фрагменте донной части чаши, в центре композиции схематично изображена человеческая фигура среди растительности. Фон изображения расписан люстром. Стенка чаши видимо была расписана растительным узором. Сохранились фрагменты от этого орнаментального пояса (рис. 2, 11). Заслуживает внимание также обломок чаши с изображением человеческой фигуры в монументальном стиле. Изображение дано на растительном фоне. У него округлое лицо, миндалевидные глаза, дугообразные брови, крошечный рот (рис. 2, 8).

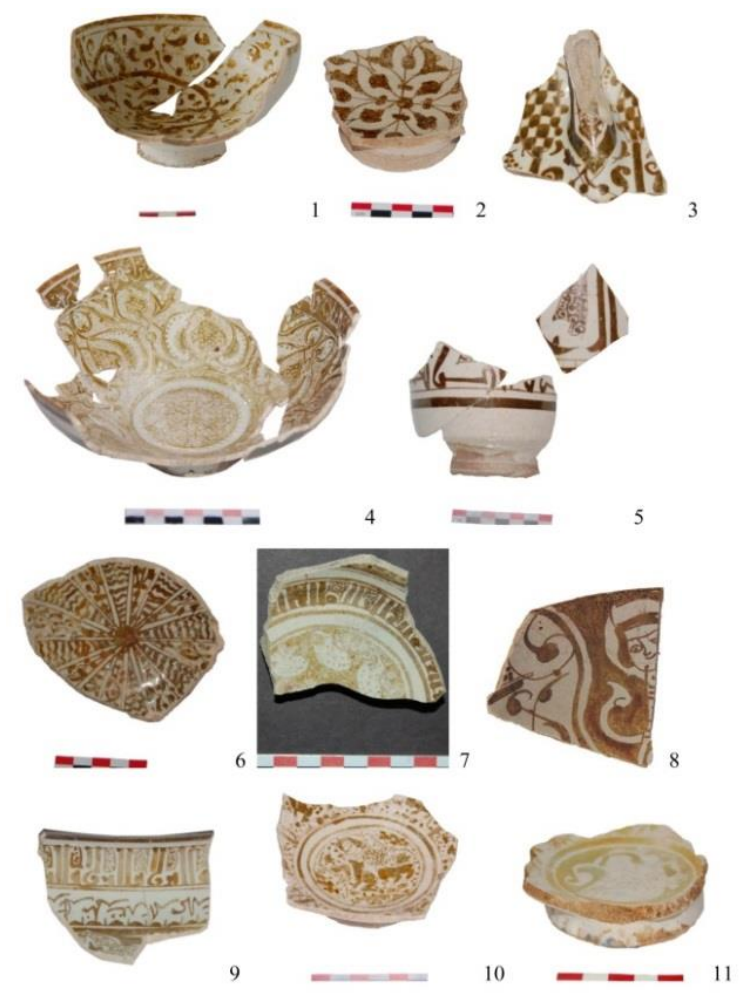

Рис.2. Фаянсы с росписью люстром по молочно-белой поливе.

Образцы с узором радиальной тектоникой, который образован путем нанесения радиальных полос, отходящих от центра и создающий сектора на поверхности посуды, немногочисленны. Заслуживает внимание фрагмент чаши с узором радиальной тектоникой, обнаруженный на раскопе VI на территории шахристана. От центра дна чаши идут 


\begin{tabular}{|c|c|c|c|c|c|c|}
\hline \multirow{4}{*}{ Impact Factor: } & ISRA (India) & $=4.971$ & SIS (USA) & $=0.912$ & ICV (Poland) & $=6.630$ \\
\hline & ISI (Dubai, UAE & $=0.829$ & РИНЦ (Russia & $=0.126$ & PIF (India) & $=1.940$ \\
\hline & GIF (Australia) & $=0.564$ & ESJI (KZ) & $=8.716$ & IBI (India) & $=4.260$ \\
\hline & JIF & $=1.500$ & SJIF (Morocec & $=5.667$ & OAJI (USA) & $=0.350$ \\
\hline
\end{tabular}

радиальные линии, которые создают как бы лучеобразные полосы, внутренность которых украшены стилизованными растительными элементами и краткими волнистыми горизонтальными линиями. Эти мотивы чередуются в лучеобразных полосах и оживляют узор, усиливая его динамичность (рис. 2, 6). Внутренняя поверхность чаши, обнаруженной на раскопе IV на территории цитадели, украшена стилизованными растительными элементами и эпиграфическим орнаментом. От центра дна чаши до орнаментального пояса, помещенного под венчиком, идут лучеобразные полосы, украшенные стилизованными растительными элементами и надписью, нанесенной почерком куфи. Композицию завершает орнаментальный пояс с эпиграфическим узором. Роспись сохранилась, неудовлетворительна, в основном стерта, прослеживаются следы (инв. 16/2015).

Таким образом, археологические раскопки позволяют констатировать, что фаянсовая посуда c росписью люстром по молочно-белой поливе широко распространилась в быту населения Шамкира.

Надо заметить, что появление люстровых изделий в Иране в последней трети XII в. связывается с миграцией египетских гончаров после пожара квартала гончаров в 1169 г. в Фустате. По мнению некоторых исследователей люстровая керамика Ирана изготовлялась лишь в Кашане [Watson, 1985, p.37- 44; Koval',2010, p. 41). Большинство исследователей полагают, что кроме Кашана, главными центрами производства этой керамики были также Рей, Султанабад, Мерв. Т.Стародуб подчеркивает, что изучение образцов люстровой керамики, хранящихся в богатейших коллекциях Тегерана, Тебриза, Мараги, Казвина убеждает в правильности предположения о существовании нескольких (а не одного) производственных центров [Starodub, 2018 , p. 380]. Надо заметить, что еще в 40-х годах Э.К.Кверфельд отмечал: «Было бы ошибочным предполагать, что найденные в различных областях люстровые изделия изготовляли в одном месте, и оттуда купцы развозили их по странам Востока и даже Запада... Можно заметить явное разнообразие в характере люстровых изделий» [Kverfel'd, 1947, p. 56]. Некоторые исследователи считают, что люстровая керамика изготовлялась и в Азербайджане. В процессе археологических раскопок в ремесленном квартале Старой Гянджи выявлены фактические материалы по производству фаянсовой посуды с люстровой росписью [Dzhafarzade, 1949, p. 74; Leviatov, 1940 , p. 33). Следует отметить, что среди фаянсовой посуды с росписью люстра, выявленной на городище Шамкир, встречаются экземпляры с производственными дефектами. Их нельзя считать импортируемым товаром из Кашана и Рея. Вполне возможно, что часть фаянсовых изделий, выявленных на городище Шамкир, была изготовлена в Азербайджане, в частности, гончарами города Гянджа. При этом основная часть люстровой керамики поступала из Кашана и Рея.

\section{Заключение}

Изучение люстровой керамики из археологических раскопок городища Шамкир позволяет констатировать, что среди различных приемов декорировки фаянсовой посуды большой эффектностью обладала роспись люстром, которая удачно сочеталась с формой изделий. Все элементы декора - геометрические и растительные орнаменты, каллиграфия и живопись гармонично связаны между собой, дополняя друг друга, создают единый и законченный художественный образ. Главенствующее положение занимали орнамент и каллиграфия. Эта керамика ярко отражает эстетические идеалы, вкус и нравы, мировоззрения сельджукской эпохи. Несомненно, фаянсовая посуда с люстровой росписью была дорогой парадной посудой, и она использовалась в быту состоятельных горожан. Топография этих артефактов показывает, что ими пользовались в основном в цитадели и в престижных кварталах шахристана. Стратиграфические наблюдения и анализ археологических комплексов позволяют констатировать, что они датируются последней четвертью XII - первой третью XIII века.

References:

1. Caiger-Smith, A. (1985). Lustre Pottery: technique, tradition and innovation in Islam and the Western world. (p.246). London: Faber and Faber.
2. Koval', V.Yu. (2010). Keramika Vostoka na Rusi IX-XVII vv. (p.269). Moscow: Nauka.

3. Lavysh, K.A. (2017). Vostochnaya i Vizantiiskaya polivnaya keramika v 


\begin{tabular}{|c|c|c|c|c|c|c|}
\hline \multirow{4}{*}{ Impact Factor: } & ISRA (India) & $=4.971$ & SIS (USA) & $=0.912$ & ICV (Poland) & $=6.630$ \\
\hline & ISI (Dubai, UAE & $=0.829$ & РИНЦ (Russia & $=0.126$ & PIF (India) & $=1.940$ \\
\hline & GIF (Australia) & $=0.564$ & ESJI (KZ) & $=8.716$ & IBI (India) & $=4.260$ \\
\hline & JIF & $=1.500$ & SJIF (Morocce & $=5.667$ & OAJI (USA) & $=0.350$ \\
\hline
\end{tabular}

srednevekovykh gorodakh Belarusi. Polivnaya keramika Sredizemnomor'ya i Prichernomor'ya $X$-XVIII вв. Tom 2. Kazan-Kishinev: Izd-vo «Stratum plus», pp. 603-624.

4. Watson, O. (2005). Ceramics from İslamic Land. (p.512). New York: Thames \& Hudson.

5. Watson, O. (1985). Persian lustre ware. (p.209). London: Faber and Faber.

6. Atagarryiev, E. (1986). Srednevekovyi Dekhistan. (p.176). L.: Nauka.

7. Starodub, T.Kh. (1990). Lyusrovaya keramika reiskogo tipa kontsa XII - nachala XIII veka kak svidetel'stvo kulturnykh svyazei Irana s Azerbaidzhanom i Srednei Azii. Kul'turnye svyazi narodov Srednei Azii i Kavkaza (drvnost' $i$ sredhevekov'e). (pp.177-184). Moscow: Nauka.

8. Dostiyev, T., Bəşirov, R., Mirzəyev, R., \& Hüseynli, N. (2013). Orta asr Şəmkir şəhəri: arxeoloji qazıntılar va artefaktlar. (p.516). Bak1: Çaşığlu.

9. Kerimov, L. (1983). Azerbaydzhanskii kover. (p.242). Baku: Izd-vo «Gyandzhlik».

10. Starodub, T. Kh. (2010). Islamskii mir: khudozhestvennaya kul'tura VII-XVII $v v$. (p.225). Moscow: Vost. lit.

11. Shelkovnikov, B.A. (1959). Fayansy, raspisannye lyustrom po beloi neprozrachnoi glazuri iz Oren-kala. Materialy $i$ issledovaniya po arkheologii SSSR, 67, M.-L.: Izd-vo AN SSSR, pp. 303-323.

12. Mason, R.B. (1997). Medieval Iranian LustrePainted and Associated Wares: Typology in a Multidisciplinary Study. Iran. V (35), pp. 103135.

13. Butkevich, L.M. (2008). Istoriya ornamenta: ucheb. posobie. (p.267). Moscow: Gumanitar, isd. Tsentr VLADOS.

14. Piotrovskii, M.B. (2001). O musul'manskom iskusstve. (p.148). SPb.: Gosudarstvennyi Ermitazh.

15. Nikalaeva, T.Yu. (2011). Transformatsiya printsipov izobrazheniya zhivykh sushchestv $\mathrm{v}$ islamskom iskusstve Irana (na primere keramiki). Vestnik MGUKI, 2 (40), pp. 238-242.

16. Starodub, T. Kh. (2018). Stilevaya identifikatsiya iranskikh lyustrov kashanskogo tipa. Sledy imperii. Kul'tura Tsentral'noi Azii ot Aleksandra Makedonskogo do Timurudov. Sb. Pamyati G.A.Puganchenkovoi. Pod red. R.G.Muradova. Kabul-Bishkek, pp. 379- 410.

17. Kverfel'd, E.K. (1947). Keramika Blizhnego Vostoka. (p.143). L.: Gosudarstvennyi Ermitazh.

18. Dzhafarzade, I.M. (1949). Istoriko arkheologicheskii ocherk Staroi Gyandzhi. (p.103). Baku: Izd-vo AN Azerb.SSR.

19. Leviatov, V.N. (1940). Keramika Staroi Gyandzhi. (p.44). Baku: Izd-vo Az.FAN SSSR. 